\title{
Using Drugs to Discriminate - Adverse Selection in the Insurance Marketplace
}

\section{Citation}

Jacobs, Douglas B., and Benjamin D. Sommers. 2015. "Using Drugs to Discriminate - Adverse Selection in the Insurance Marketplace." N Engl J Med 372 (5) (January 29): 399-402.

\section{Published Version}

doi:10.1056/NEJMp1411376

\section{Permanent link}

http://nrs.harvard.edu/urn-3:HUL.InstRepos:14008379

\section{Terms of Use}

This article was downloaded from Harvard University's DASH repository, and is made available under the terms and conditions applicable to Other Posted Material, as set forth at http:// nrs.harvard.edu/urn-3:HUL.InstRepos:dash.current.terms-of-use\#LAA

\section{Share Your Story}

The Harvard community has made this article openly available.

Please share how this access benefits you. Submit a story.

\section{Accessibility}


health insurance but more acceptable to discriminate for products such as life, disability, and longterm care insurance. In defending the right to such discriminatory underwriting, insurers have claimed that if applicants have relevant information that isn't available to insurers, such as robust genetic risk information, low-risk consumers will drop out of the mix and higher-risk consumers will disproportionately purchase coverage, forcing companies to raise prices and causing a "death spiral" of adverse selection.

This concern was largely theoretical until we showed that healthy people with higher-risk results on predictive genetic testing were more likely to use that information to make decisions about purchasing long-term care insurance. ${ }^{5}$ If this finding is generalizable, then for insurance products that remain outside GINA's scope, the status quo is unlikely to last. As more people obtain their own genetic risk information, companies selling such products may feel forced to test customers genetically in order to stratify customer risk. Alternatively, we may eventually have to abandon risk-based underwriting and adopt a more unitary pricing system that pools risk.
The standard argument for regulating risk classification is that it's unfair for employers to discriminate or insurers to charge different rates because of immutable risks. GINA's exceptionalism may, in part, reflect a genetic determinism and therapeutic nihilism that were prevalent in 1995, when Congress first considered this issue, but that will be far less salient in the future. Although genetic determinism with regard to highly penetrant mendelian conditions may persist, it's now clear that everyone carries genetic variants that will influence, but in most cases not exclusively determine, one's health status. The science of genomic medicine is moving rapidly toward multiscale network and systems biology by elucidating the complex interactions of genomics, physiology, and environmental influences. In a future informed by this science, we may be able to personalize risk stratification and then tailor diet, exercise, and pharmaceuticals and even edit genes to promote wellness by preventing and minimizing illness. Eventually, the notion of immutable genetic risks may become obsolete, and it may be less important to grant genetic information special protection than to protect everyone from all forms of medical discrimination. As all medicine in a sense becomes genomic medicine, perhaps the genetic nondiscrimination secured by GINA will translate into nondiscrimination in all of medicine.

Disclosure forms provided by the authors are available with the full text of this article at NEJM.org.

From the Division of Genetics, Brigham and Women's Hospital (R.C.G., D.L.); Partners Personalized Medicine (R.C.G.); the Broad Institute (R.C.G.); and Harvard Medical School (R.C.G.) - all in Boston; and the Center for Medical Ethics and Health Policy, Baylor College of Medicine, Houston (A.L.M.).

1. Parkman AA, Foland J, Anderson B, et al. Public awareness of genetic nondiscrimination laws in four states and perceived importance of life insurance protections. J Genet Couns 2014 September 23 (Epub ahead of print).

2. Buhrmester M, Kwang T, Gosling SD. Amazon's Mechanical Turk: a new source of inexpensive, yet high-quality, data? Perspect Psychol Sci 2011;6:3-5.

3. Vassy JL, Lautenbach DM, McLaughlin $\mathrm{HM}$, et al. The MedSeq Project: a randomized trial of integrating whole genome sequencing into clinical medicine. Trials 2014; 15:85-97.

4. Bard JS. When public health and genetic privacy collide: positive and normative theories explaining how ACA's expansion of corporate wellness programs conflicts with GINA's privacy rules. J Law Med Ethics 2011; 39:469-87.

5. Taylor DH Jr, Cook-Deegan RM, Hiraki S, Roberts JS, Blazer DG, Green RC. Genetic testing for Alzheimer's and long-term care insurance. Health Aff (Millwood) 2010;29: 102-8.

DOI: 10.1056/NEJMp1404776

Copyright @ 2015 Massachusetts Medical Society.

\title{
Using Drugs to Discriminate - Adverse Selection in the Insurance Marketplace
}

\author{
Douglas B. Jacobs, Sc.B., and Benjamin D. Sommers, M.D., Ph.D.
}

7 liminating discrimination on the basis of preexisting conditions is one of the central features of the Affordable Care Act
(ACA). Before the legislation was passed, insurers in the nongroup market regularly charged high premiums to people with chronic conditions or denied them coverage entirely. To address these problems, the ACA instituted ageadjusted community rating for 


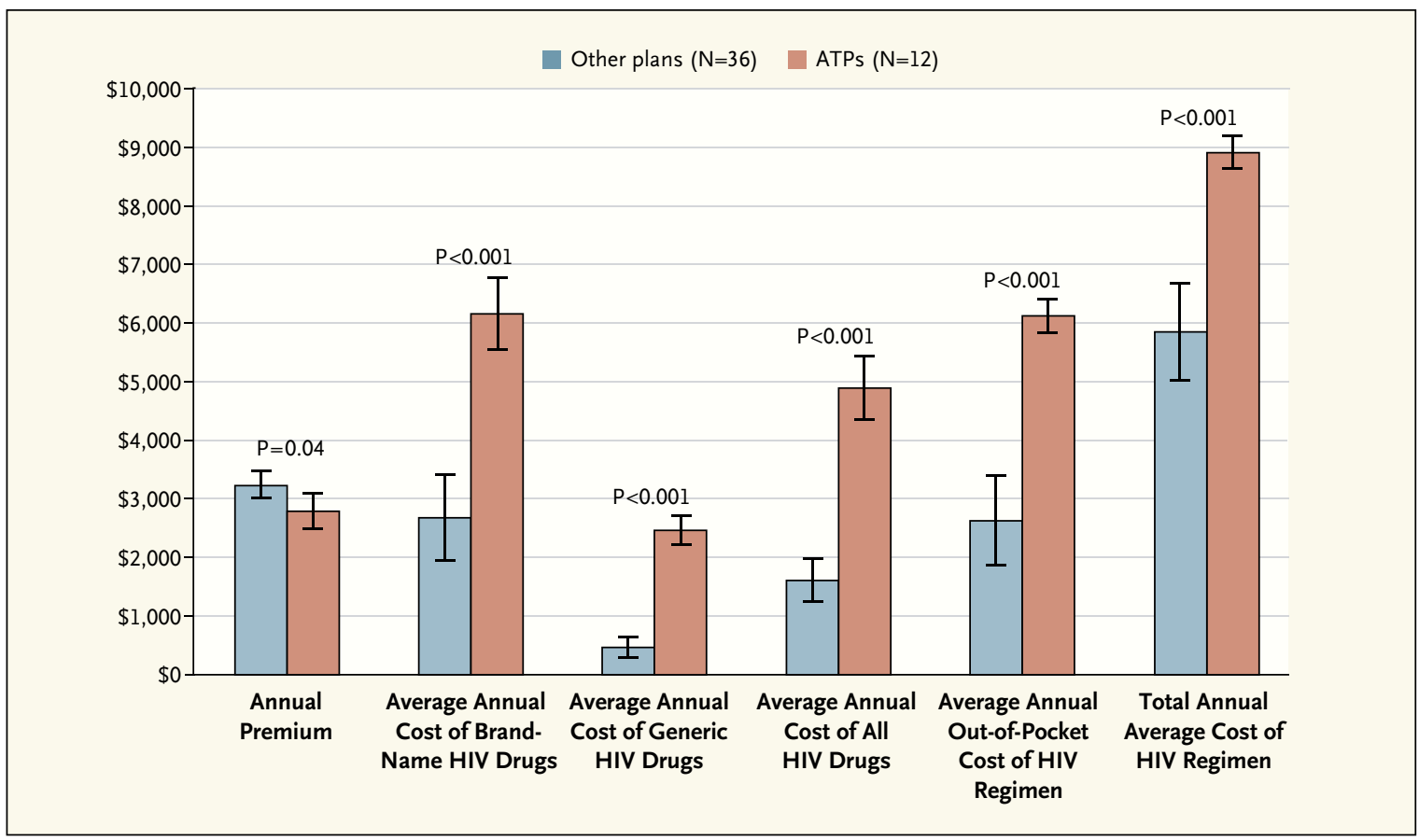

Average HIV-Related Costs for Adverse-Tiering Plans (ATPs) versus Other Plans.

I bars represent $95 \%$ confidence intervals, and $\mathrm{P}$ values represent results of $\mathrm{t}$-tests for significant differences between ATPs and other plans for each outcome. The "total annual average cost of HIV regimen" is the sum of the annual premium and the average annual out-of-pocket cost of HIV regimens. The HIV treatment regimen that was used for this calculation was emtricitabine, tenofovir, and efavirenz, a commonly prescribed single-pill regimen. Out-of-pocket spending was capped at each plan's out-of-pocket maximum under the Affordable Care Act, typically \$6,350.

premiums and mandated that plans insure all comers. In combination with premium subsidies and the Medicaid expansion, these policies have resulted in insurance coverage for an estimated 10 million previously uninsured people in $2014 .{ }^{1}$

There is evidence, however, that insurers are resorting to other tactics to dissuade high-cost patients from enrolling. A formal complaint submitted to the Department of Health and Human Services (HHS) in May 2014 contended that Florida insurers offering plans through the new federal marketplace (exchange) had structured their drug formularies to discourage people with human immunodeficiency virus (HIV) infection from selecting their plans.
These insurers categorized all HIV drugs, including generics, in the tier with the highest cost sharing. ${ }^{2}$

Insurers have historically used tiered formularies to encourage enrollees to select generic or preferred brand-name drugs instead of higher-cost alternatives. But if plans place all HIV drugs in the highest cost-sharing tier, enrollees with HIV will incur high costs regardless of which drugs they take. This effect suggests that the goal of this approach which we call "adverse tiering" - is not to influence enrollees' drug utilization but rather to deter certain people from enrolling in the first place.

To explore the implications of this practice, we analyzed adverse tiering in 12 states using the federal marketplace: 6 states with insurers mentioned in the HHS complaint (Delaware, Florida, Louisiana, Michigan, South Carolina, and Utah) and the 6 most populous states without any of those insurers (Illinois, New Jersey, Ohio, Pennsylvania, Texas, and Virginia; for details, see the Supplementary Appendix, available with the full text of this article at NEJM.org). We examined the plans with the lowest, secondlowest, median, and highest premiums on the "silver" level in each state, analyzing formularies and benefit summaries to assess cost sharing for nucleoside reverse-transcriptase inhibitors (NRTIs), one of the most commonly prescribed classes of 
HIV medications. We chose this example because HIV is associated with high insurance costs, requires lifelong treatment, and is treated with an expensive and disease-specific class of medications. We defined adverse tiering as placement of all NRTIs in tiers with a coinsurance or copayment level of at least $30 \%$. In estimating enrollees' average annual medication costs, we used the negotiated drug price paid by Humana, which makes its prices available online.

We found evidence of adverse tiering in 12 of the 48 plans 7 of the 24 plans in the states with insurers listed in the HHS complaint and 5 of the 24 plans in the other six states (see the Supplementary Appendix for sample formularies). The differences in out-of-pocket HIV drug costs between adverse-tiering plans (ATPs) and other plans were stark (see graph). ATP enrollees had an average annual cost per drug of more than triple that of enrollees in non-ATPs $(\$ 4,892$ vs. $\$ 1,615)$, with a nearly $\$ 2,000$ difference even for generic drugs. Fifty percent of ATPs had a drug-specific deductible, as compared with only $19 \%$ of other plans. Even after factoring in the lower premiums in ATPs and the ACA's cap on out-of-pocket spending, we estimate that a person with HIV would pay more than $\$ 3,000$ for treatment annually in an ATP than in another plan.

Our findings suggest that many insurers may be using benefit design to dissuade sicker people from choosing their plans. A recent analysis of insurance coverage for several other high-cost chronic conditions such as mental illness, cancer, diabetes, and rheumatoid arthritis showed sim- ilar evidence of adverse tiering, with $52 \%$ of marketplace plans requiring at least $30 \%$ coinsurance for all covered drugs in at least one class. ${ }^{3}$ Thus, this phenomenon is apparently not limited to just a few plans or conditions.

Adverse tiering is problematic for two reasons. First, it puts substantial and potentially unexpected financial strain on people with chronic conditions. These enrollees may select an ATP for its lower premium, only to end up paying extremely high out-ofpocket drug costs. These costs may be difficult to anticipate, since calculating them would re- in drug-plan design. Although the ACA's risk-adjustment, reinsurance, and risk-corridor programs provide some financial protection to insurers whose enrollees are sicker than average, the existence of adverse tiering in 2014 suggests that selection opportunities remain. Furthermore, the reinsurance and risk-corridor programs will be phased out after 2016, which will only increase insurers' incentives to avoid sick enrollees.

Several policies could reduce the harms associated with adverse tiering. One approach to addressing unexpectedly high out-of-

\section{Adverse tiering will most likely lead to adverse selection over time, with sicker people clustering in plans that don't use adverse tiering for their medical conditions.}

quire knowing an insurer's negotiated drug prices - information that is not publicly available for most plans.

Second, these tiering practices will most likely lead to adverse selection over time, with sicker people clustering in plans that don't use adverse tiering for their medical conditions. After enrollees with chronic conditions realize they're incurring higher-thanexpected costs in an ATP, some will switch to different plans during the next enrollment period. Over time, thanks to word-ofmouth or clinicians' advice, plans offering generous prescriptiondrug benefits may see a large influx of sick enrollees, which would reduce their profits and could lead to a race to the bottom pocket costs for people with chronic conditions is price transparency. Insurers could be required to list on their formulary each drug's "estimated price to enrollee," based on the negotiated price and the copayment or coinsurance. However, if adopted in isolation, price transparency would probably accelerate the adverse-selection process.

Additional policies are needed to combat selection and end adverse tiering altogether. One potential approach with a policy precedent would be establishing protected conditions in drug formularies. Medicare Part D has designated several "protected classes" of drugs, including those used for HIV, seizures, and cancer, in order to maintain patients' 
access to them. A similar approach in the marketplaces could set an upper limit on cost sharing for medications for protected conditions. Such a policy would reduce financial exposure for people with these conditions, even if they chose suboptimal plans - which, to judge from studies of consumers' plan selection, is likely to remain a common occurrence. ${ }^{4}$ Other safeguards for protected conditions, such as limits on priorauthorization requirements, could also be implemented.

An important additional step would be to require marketplace plans to offer drug benefits that meet a given actuarial value meaning that the percentage of drug costs paid by the plan (rather than the consumer) would have to exceed a particular threshold. This level could be set at the overall actuarial value for a given plan (i.e., $70 \%$ for silver plans) or above it. Under this approach, in order to significantly increase cost sharing for one drug, an insurer would have to reduce cost sharing for another drug. This step is crucial because it encompasses treatment of all health conditions - not just protected conditions - and addresses nonformulary-based methods of passing costs on to consumers (e.g., drug-specific deductibles) that may induce adverse selection.

Stopping adverse drug tiering will not completely eliminate discrimination in the insurance marketplace. Some insurers will invariably think of new ways to dissuade sick enrollees from joining their plans. Eliminating premium discrimination on the basis of health status was one of the ACA's chief accomplishments in the nongroup insurance market and one of the law's most popular features. ${ }^{5}$ Preventing other forms of financial discrimination on the basis of health status - with the attendant risks of adverse selection in the marketplace will require ongoing oversight. The ACA has already made major inroads in designing a more equitable health care system for people with chronic conditions, but the struggle is far from over.
Disclosure forms provided by the authors are available with the full text of this article at NEJM.org.

From the Department of Health Policy and Management, Harvard School of Public Health, Boston.

1. Sommers BD, Musco T, Finegold K, Gunja MZ, Burke A, McDowell AM. Health reform and changes in health insurance coverage in 2014. N EnglJ Med 2014;371:867-74.

2. The AIDS Institute and the National Health Law Program. Administrative complaint re: discriminatory pharmacy benefits design in select qualified health plans in Florida (http://www.healthlaw.org/component/ jsfsubmit/showAttachment?tmpl=raw\&id= 00Pd000000B9TMYEA3).

3. Pharmaceutical Research and Manufacturers of America. An analysis of exchange plan benefits for certain medicines. Avalere, June 2014 (http://www.phrma.org/affordable -care-act/coverage-without-access-an-analysis -of-exchange-plan-benefits-for-certain -medicines).

4. Abaluck J, Gruber J. Choice inconsistencies among the elderly: evidence from plan choice in the Medicare Part D program. Am Econ Rev 2011;101:1180-210.

5. Zengerle P. Most Americans oppose health law but like provisions. Reuters. June 24, 2012 (http://www.reuters.com/article/ 2012/06/25/us-usa-campaign-healthcare -idUSBRE85N01M20120625).

DOI: 10.1056/NEJMp1411376

Copyright (C) 2015 Massachusetts Medical Society.

\title{
Death Takes a Weekend
}

\author{
Perri Klass, M.D.
}

Twanted my mother to write this essay. My mother was a writer all her life - novels, memoirs, essays, even blog entries - and in recent years she'd written some articles about aging and illness, about the indignities of becoming less independent. ${ }^{1,2}$ So when she got sick, I decided that when she was better, I would urge her to write a piece about being in the hospital
- about pain and fear and comfort and cure, but also about unexpected revelations of hospital routine and custom, as seen from the patient's perspective. I even kept a list of topics for her, and the first one was the hospital weekend. Not too charged, I thought, not too personal - a good way to broach the subject of being a patient and to write about a practical problem while touching on the fear and pain underneath. She would write it when she was better, when she was home, when she was cured. But there was no comfort and no cure, so here I am.

From the physician's perspective, weekends in the hospital are all about coverage. I remember, during residency, feeling that the attendings brought in doughnuts for weekend rounds because the 